\title{
Is choice of general practitioner important for patients having coronary artery investigations?
}

Department of Epidemiology and Public Health, Queen's University of Belfast, Belfast

F Kee, honorary senior lecturer

Eastern Health and Social Services Board B Gaffney, consultant in public health medicine

$\mathrm{J}$ Little, director of public health

Northern Health and Social Services Board C Canavan, research assistant, department of public health medicine J D Watson, director of public health

Western Health and Social Services Board W McConnell, director of public health

Southern Health and Social Services Board A $M$ Telford, director of public health

Correspondence to:

Dr F Kee, Department of Public Health Medicine,

Northern Health and Social Services Board, County Hall, Ballymena BT42 1QB Accepted for publication 31 March 1994

\begin{abstract}
Objective-To determine whether particular sociodemographic characteristics of patients with stable angina affected their general practitioners' (GPs') decisions to refer them for revascularisation assessment.

Design-Postal questionnaire survey. Setting-Collaborative survey by the departments of public health medicine in each of the four health boards in Northern Ireland, serving a total population of 1.5 million.
\end{abstract}

Subjects-All (962) GPs.

Main measures-The relation between GPs' referral decisions and patients' age, sex, employment status, home circumstances, smoking habits, and obesity.

Results-541 GPs replied (response rate $56 \%$ ). Most were "neutral" towards a patient's sex $(428,79 \%)$, weight (331, $61 \%$ ), smoking habit $(302,56 \%)$, employment status $(431,80 \%)$, and home circumstances $(408,75 \%)$ in making decisions about referral. In assigning priority for surgery most were neutral towards the patient's sex $(459,85 \%)$, employment status $(378,70 \%)$, and home circumstances $(295,55 \%)$. However, most GPs $(518,95 \%)$ said that younger patients were more likely to be referred, and a significant minority were less likely to refer patients who smoked $(202,37 \%)$ and obese patients $(175,32 \%)$ and more likely to refer employed patients $(97,18 \%)$ and those with dependants $(117,22 \%)$ (compared with patients with otherwise comparable clinical characteristics); these views paralleled the priority which GPs assigned these groups. The stated likelihood of referral of young patients was independent of the GPs' belief in ability to benefit from revascularisation, but propensity to refer and perception of benefit were significantly associated for all other patient characteristics.

Conclusion-GPs' weighting of certain characteristics in reaching decisions about referral for angiography is not uniform and may contribute to unequal access to revascularisation services for certain patient groups.

(Quality in Health Care 1994;3:17-22)

\section{Introduction}

In October 1992 the chief medical officer for Northern Ireland made several recommendations concerning the provision of cardiac surgery services in the province, ${ }^{1}$ recognising not only the need to increase local capacity but also to rationalise the organisation of the services. Among the issues he raised were the concerns of some doctors about unequal access to treatment for certain groups of patients and the need to establish clear criteria for referral for investigation and revascularisation assessment. Indeed, there is some evidence of apparent inequity in the rates of angiography between different areas of the province $^{2}$ and of disproportionately low rates among women. ${ }^{3}$ The chief medical officer recognised the pivotal role of the patient's general practitioner (GP) and local hospital specialists but, though he acknowledged the lack of hard data, he suggested there was little consistency among clinicians in the approach to referral. At the same time, some who gave evidence to the chief medical officer considered that the overall rate of angiography $(200 / 100000$ or roughly twice that in many English districts) was excessive.

This paper reports a survey of the views of GPs about their routine management of patients with stable angina; it aimed at determining patient characteristics which GPs felt influenced their decisions to refer for angiography and revascularisation assessment.

\section{Methods}

Family practitioner services in Northern Ireland are organised by four health and social services boards, serving a population of 1.5 million. After a pilot study a questionnaire was sent to all 962 GPs providing services in the boards' areas. The covering letter, issued in October 1993, explained that the purpose of the survey was to address some of the issues raised by the chief medical officer's report and to assess the GPs' usual approaches to managing chronic stable angina. The questionnaires were identified by a code number to allow the posting of one reminder letter, and the doctors were assured that their responses would be treated strictly confidentially.

Among the primary issues raised by the questionnaire, the doctors were asked whether demographic or clinical factors (severe symptoms, relatively young patients, male sex, employment, dependants, smoking, obesity) influenced their decision to refer patients with chronic stable angina to a cardiologist for assessment; their belief about the ability of particular groups of patients to benefit from revascularisation; and the priority (on the surgical waiting list) which it was justifiable to 
accord to patients with specific characteristics (compared with patients without the specified features) (box).

8 In regard to patients aged 70 or less, do any of the following factors affect the likelihood that you will refer a patient for assessment of suitability for revascularisation compared with other patients without the specified characteristic?

(Please indicate by circling the appropriate response, whether the factor would increase, decrease, or not affect your decision to refer)

$\begin{array}{llll}\text { Severe symptoms } & \text { Increase } & \text { Decrease } & \text { No change } \\ \text { Relatively young patients } & \text { Increase } & \text { Decrease } & \text { No change } \\ \text { Male patients } & \text { Increase } & \text { Decrease } & \text { No change } \\ \text { Employed patients } & \text { Increase } & \text { Decrease } & \text { No change } \\ \text { Patients with dependants } & \text { Increase } & \text { Decrease } & \text { No change } \\ \text { Patients who smoke } & \text { Increase } & \text { Decrease } & \text { No change } \\ \text { Obese patients } & \text { Increase } & \text { Decrease } & \text { No change }\end{array}$

9 Do you believe that patients of the types shown below have an increased, decreased, or no different chance of benefiting from revascularisation compared with patients without the specified characteristics?

Patients with severe Increased Decreased No different
symptoms

Relatively young patients

Increased Decreased No different

Male patients

Increased Decreased No different

Employed patients

Increased Decreased No different

Patients with dependants

Increased

Decreased No different

Patients who smoke

Increased

Decreased No different

Obese patients

Increased Decreased No different

10 Cardiac surgeons in the United Kingdom prioritise their waiting lists for bypass operations in several different ways. Other than the degree of anatomical stenosis of the coronary vessels and the ventricular ejection fraction, which of the following factors do you feel it reasonable for the surgeon to take account of in deciding the priority given to patients?

(Please indicate by circling the appropriate response whether the factor would increase, decrease, or not affect the priority of the patient compared with other patients without the characteristic

\begin{tabular}{llll} 
Severe symptoms & Increase & Decrease & No change \\
Relatively young patients & Increase & Decrease & No change \\
Male patients & Increase & Decrease & No change \\
Employed patients & Increase & Decrease & No change \\
Patients with dependants & Increase & Decrease & No change \\
Patients who smoke & Increase & Decrease & No change \\
Obese patients & Increase & Decrease & No change \\
\hline
\end{tabular}

Relevant parts of questionnaire

Figs 1-4 General practitioners' responses to patients with chronic stable angina with respect to (a) likelihood of referral, (b) ability of patient to benefit from revascularisation, and (c) priority accorded on list
After coding the data were analysed with SPSS for Windows software. The practice size of the responders and non-responders was compared with the $t$ test for independent samples. Differences in the proportions of doctors giving particular responses were assessed with the $\chi^{2}$ statistic for contingency tables. When appropriate, Fisher's exact test was applied.

\section{Results}

Of the 962 GPs surveyed, 541 replied, a response rate of $56 \%$; female GPs were slightly under-represented $(114,21 \%$ of responders $v$ $118,28 \%$ of non-responders; $\chi^{2}=13$, $\mathrm{p}=0.0015)$. Response rates were lower in practices with fewer patients living in deprived areas $(61 \%$ in the lowest tertile and $44 \%$ in highest tertile of practices; $\chi^{2}=36$, $\mathrm{p}<0.0001)$. There was no significant difference in the average practice size of the responders and non-responders (6103 $v 6337$; $t=1 \cdot 19, \mathrm{p}=0 \cdot 23$ ).

As indicated in the questionnaire the GPs were asked to say whether, for patients with stable angina (with otherwise comparable clinical characteristics), certain features increased the likelihood that they would refer particular patients to a cardiologist compared with patients without the specific features (for example, young patients versus old patients, men versus women, obese patients versus nonobese patients, etc).

Figures 1 to 6 summarise the results and also show the numbers of doctors believing that a particular characteristic affected the patient's ability to benefit (from revascularisation) and that the characteristic should affect the patient's priority on the waiting list. Most of these GPs were "neutral" towards a patient's sex (428, 79\%), weight (331, 61\%), smoking habit $(302,56 \%)$, employment status $(431,80 \%)$, and home circumstances (408, $75 \%)$ in making decisions about referral for revascularisation assessment. In their assignment of priority for surgery most were neutral towards the patient's sex $(459,85 \%)$, employment status $(378,70 \%)$, and home circumstances $(295,55 \%)$. However, most GPs $(572,95 \%)$ said that relatively young patients were more likely to be referred than older patients, and a significant minority were less likely to refer smokers $(202,37 \%)$ and obese patients $(175,32 \%)$ and more likely to refer employed patients $(98,18 \%)$ and those with dependants $(117,22 \%)$ (compared with patients with otherwise comparable clinical characteristics), views which paralleled the priority which they assigned these groups.

Except for age, there was a significant relation for all of the other patient characteristics between the likelihood of referral and the perception of benefit (table 1). Table 2 shows the association between the perception of the patient's ability to benefit and the priority on the waiting list which the doctors felt it justifiable to accord to particular types of patients. The stated propensity to refer relatively young patients was independent of the perception of benefit for the patient, but 


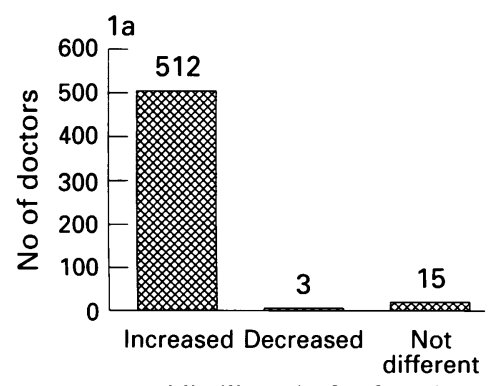

Likelihood of referral
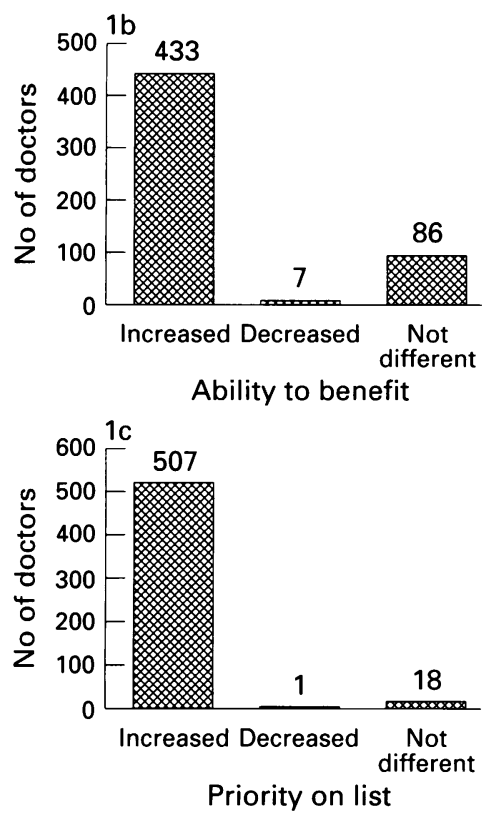

Figure 1 Relatively young patients
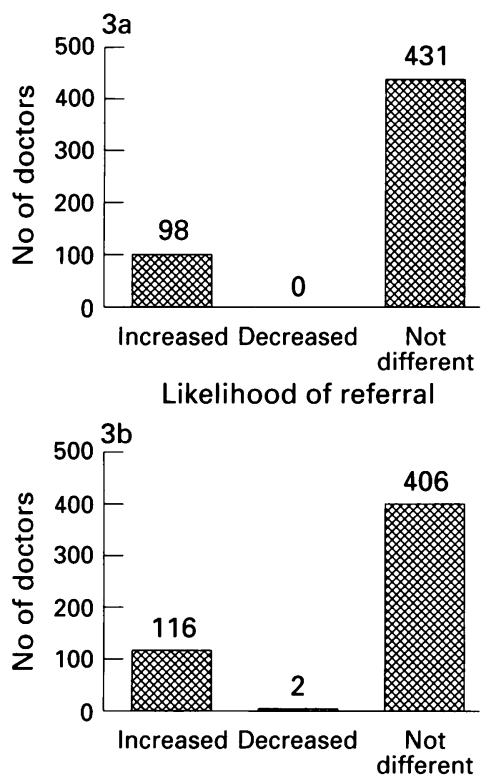

Ability to benefit

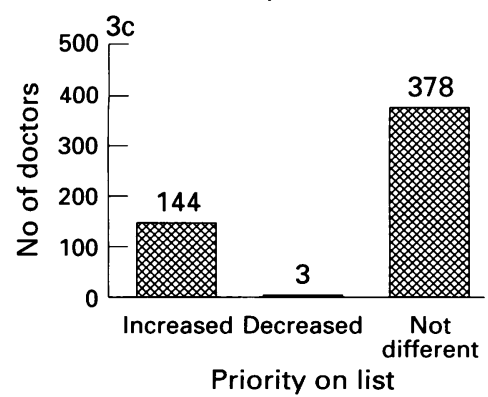

Figure 3 Employed patients

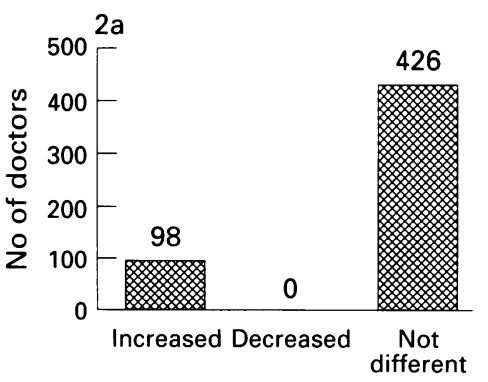

Likelihood of referral
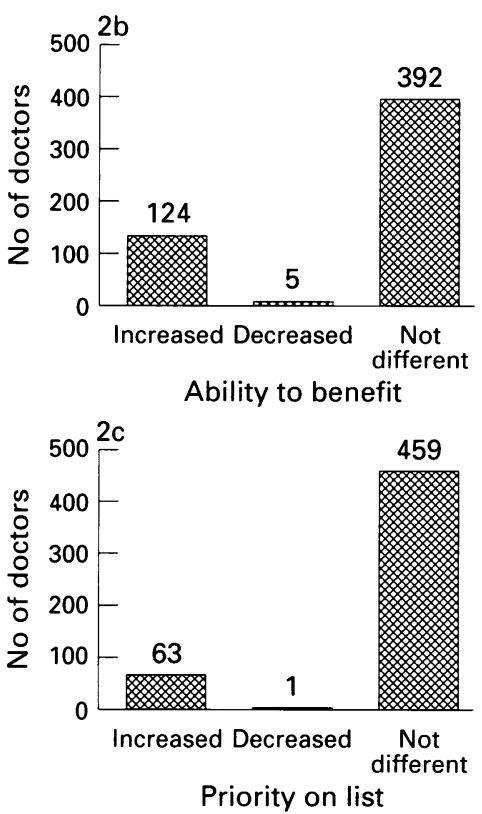

Figure 2 Male patients

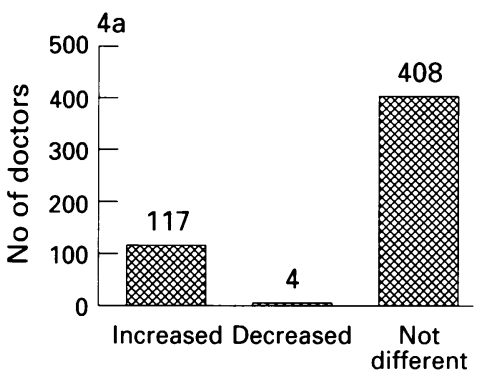

Likelihood of referral

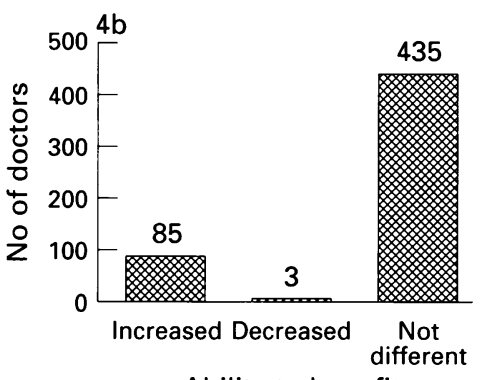

Ability to benefit

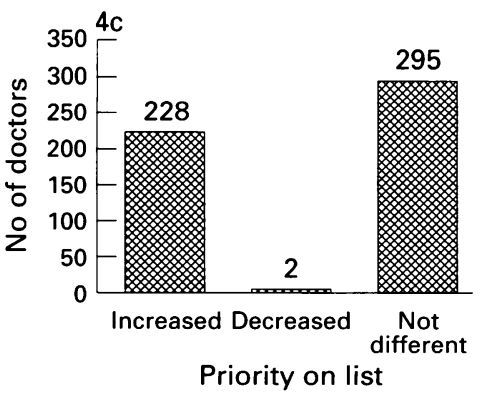

Figure 4 Patients with dependants significant associations were evident for the other patient characteristics.

Some differences were apparent in the responses of male and female doctors. A higher proportion of the male GPs indicated a greater propensity to refer employed patients and those with dependants (table 3). Male GPs were also significantly more likely than female GPs to accord a higher priority on the waiting list to employed patients and those with dependants and a lower priority to obese patients (table 4 ).

\section{Discussion}

Our results give some insight into the sociodemographic characteristics of patients with chronic stable angina which GPs consider influence their decisions about referral for revascularisation assessment. With few exceptions, GPs' propensity to refer specific types of patients (and the priority on the waiting list which they accorded them) paralleled their belief about the patient's ability to benefit from bypass surgery. Though this tends to suggest rational decision making, it may not reflect good clinical judgement if the prior beliefs about ability to benefit from revascularisation are suspect. If this were so, it could contribute to inequity of access to these services for certain patient groups.

Most GPs said they were more likely to refer younger patients (though a cut off age was not defined), and most believed that younger patients had a greater chance of benefiting from bypass surgery. This finding bears out a recent study that showed that older subjects present at angiography later in the course of the disease and are receiving more intense treatment. ${ }^{4}$ There is little evidence that older subjects are less likely to benefit than younger subjects, ${ }^{5 a}$ and in fact the survival advantage conferred by surgery in the European coronary surgery study was greater in older subjects..$^{5 b}$ Although predicting the risk of death or infarction for individuals is difficult on the basis of angiographic results, ${ }^{6}$ the absolute risks of adverse events in older subjects is generally higher. Seldom are patients given the opportunity to weigh the risks and benefits, ${ }^{7}$ and we wonder whether these responses reflect a form of agism. ${ }^{8}$ However, it has been convincingly argued that the chronological age of a patient is an inadequate criterion on which to base decisions regarding medical care. ${ }^{9}{ }^{10}$ It is possible, nevertheless, that older patients complain less, for there is some evidence that the perception of angina is reduced with age. ${ }^{11}$

A sizable majority of doctors felt that men and women had equal chances of benefiting from bypass surgery. However, roughly one in five $(124,23 \%)$ thought that male patients had a greater chance of benefit, and about the same proportion $(98,18 \%)$ said they were more likely to refer men for assessment. Though women are considered to experience higher operative risks, ${ }^{7}$ there is also some evidence of systematic differences between male and female patients in rates of angiography ${ }^{3}$ and in referral for surgery. ${ }^{12}$ Female 

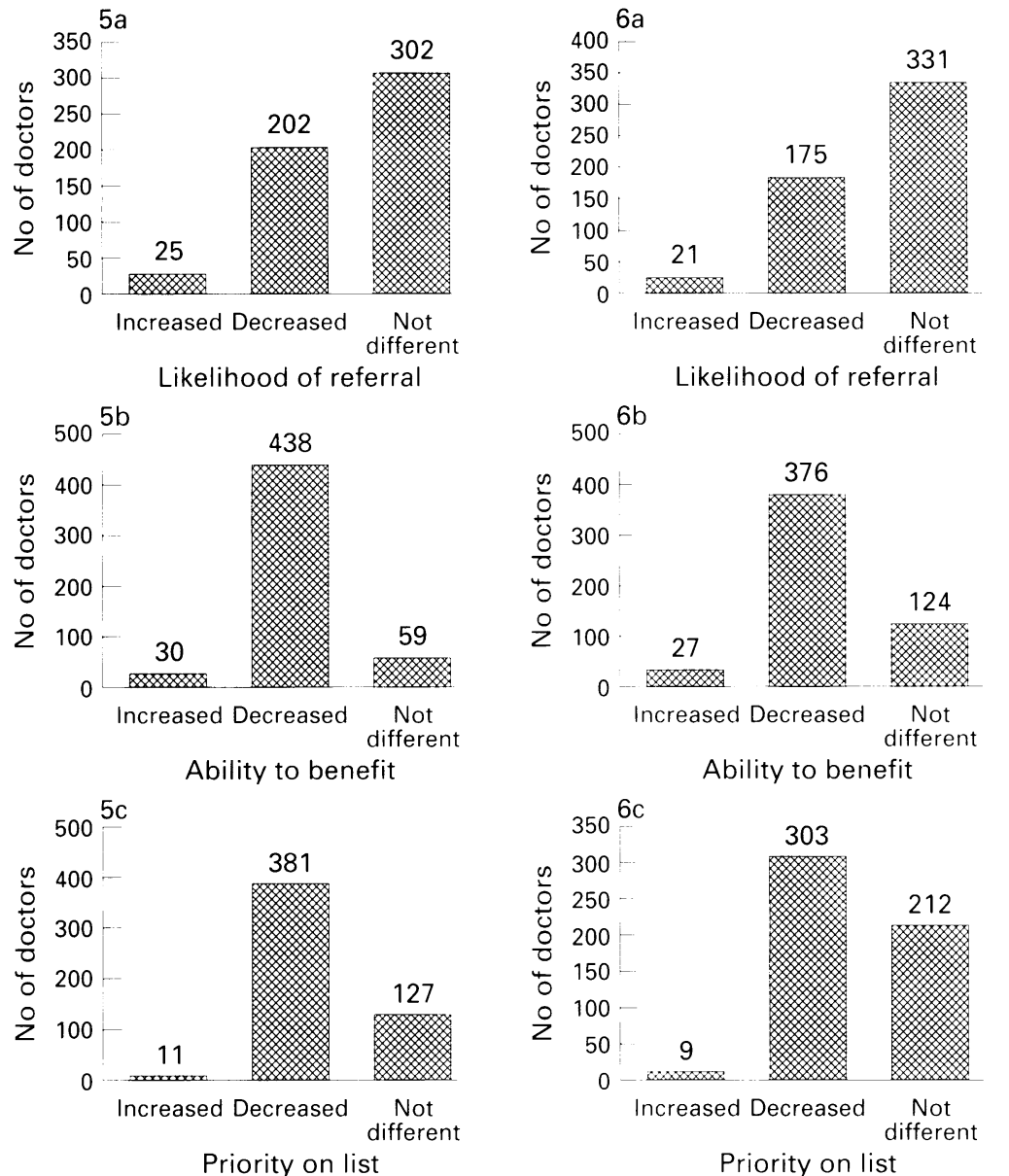

Figure 5 Patients who smoke

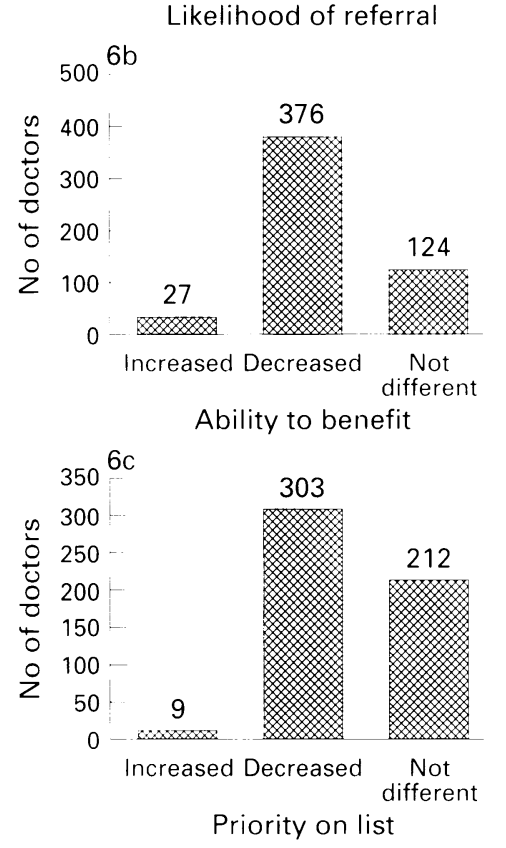

Figure 6 ()bese pationts

Figs 5-6 General practitioners' responses to pationts with chronic stable angina with respect to (a) likelihood of referral, (b) ability of patient to benefit from revascularisation, and (c) priority accorded on list

patients seem to report angina symptoms less reliably,,$^{13}$ and the clinical management of female patients is strongly influenced by the patient's presentation "style." 14 There are also some differences in the clinical presentation and range of disease in the two sexes. ${ }^{15}$ is Thus we do not know whether our findings reflect bias in a minority of doctors. Certainly male and female doctors in our sample held similar views in this regard.

Although 438 doctors thought that patients who smoked would benefit less from revascularisation, less than half (202) said that the likelihood of their referring such patients was any lower. However $381(70 \%)$ felt it justifiable to accord such patients a lower priority on the surgical waiting list. There is evidence that smoking accelerates graft occlusion ${ }^{19} 20$ and that the benefits of surgery in this group are smaller. ${ }^{21}$ In this context the GPs might have been considered to be utilitarian and fair in their decisions. However, other patient characteristics may reduce the chances of benefit, such as diabetes or elusive genetic factors, ${ }^{22}$ which seldom feature in the debate on priorities for surgery. A major weakness of the utilitarian approach is that, ultimately, judgements have to be made about the welfare of different types of people ${ }^{8}$ and, arguably, value of life can only sensibly be judged by patients themselves. ${ }^{23}$ Though two thirds of doctors said that their referral decisions were

unaffected by a patient's obesity, a third said that they would accord such patients a lower priority on the waiting list. The debate on the appropriateness of such decisions might share much in common with the arguments rehearsed for smoking.

Though most GPs said they were uninfluenced by a patient's employment status or the home circumstances (whether or not there were dependants), roughly one in five admitted that they were more likely to refer employed patients and those with dependants and would accord these patients a higher waiting list priority. This was particularly characteristic of male doctors. Though there is no direct evidence on how these factors affect the outcome of bypass surgery, low levels of social and economic resources identify an important high risk group among medically treated patients with coronary artery disease, independent of medical prognostic factors. ${ }^{21}$ In one study the number of individuals dependent on the household income was inversely related to survival. ${ }^{2+}$ The views of these Northern Ireland GPs parallel those of a group of Canadian surgeons who were strongly influenced by a patient's work status in assigning waiting list priority. ${ }^{25}$ In fact, the mean shift in priority due to work status was equal to or larger than the mean shift due to clinical factors such as severity of angina. ${ }^{25}$

In summary, we showed that most of these GPs were fairly "neutral" towards a patient's sex, weight, smoking habit, or home circumstances in making decisions about referral for revascularisation assessment and their assignment of priority. However, most GPs said that younger patients were more likely to be referred and a significant minority were less likely to refer patients who smoked and obese patients and more likely to refer employed patients and those with dependants, views which paralleled the priority which they assigned these groups. Since the timeliness of revascularisation is ultimately dependent on the point of entry of the patient "into the system" (that is, after the initial referral) we believe these findings may have a bearing on equity of access bypass surgery. We qualify our conclusions with three principal caveats, as follows.

Firstly, our response rate was only $56 \%$. However, this is twice the response rate of a recent national survey of GP referrals for angiography ${ }^{20}$ carried out by the National Heart and Lung Hospital, and we consider it unlikely that non-responders would have been better informed about the benefits offered by surgery for particular types of patients. Secondly, we have not measured the GPs' actual referral rates of patients for revascularisation assessment. Although death rates from heart disease are higher in Northern Ireland than in the rest of the United Kingdom, the prevalence of angina is comparable, ${ }^{27}$ but the number of angiograms performed in the province in 1991 (3087 for a total population of 1.5 million) was twice that which would be predicted on the basis of a recently devised "population needs" algorithm..$^{2 \$}$ Despite this generous "capacity" there are still consider- 


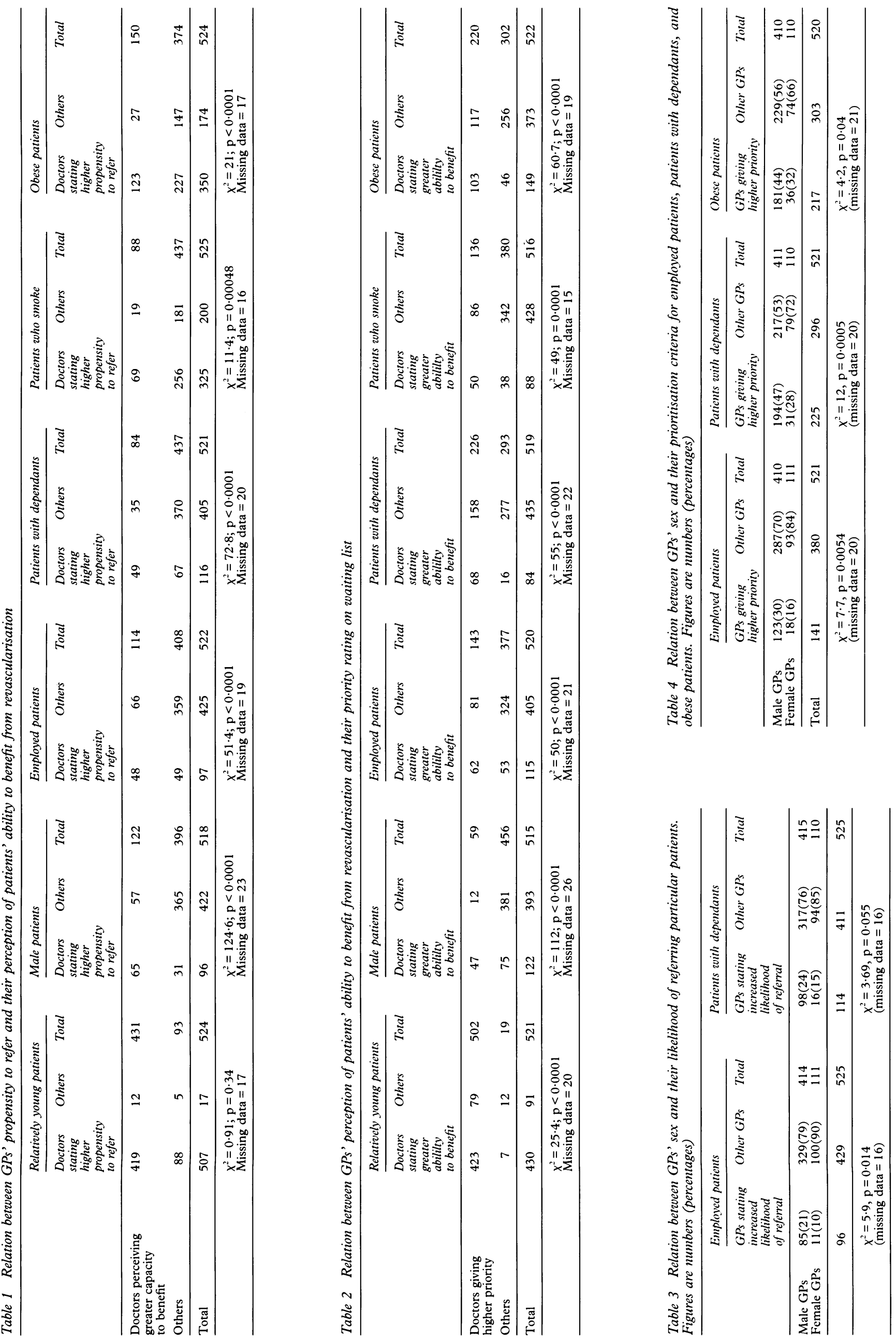

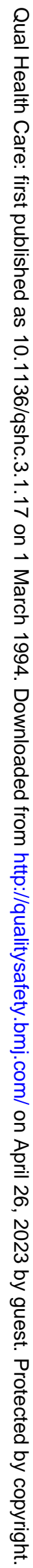


able disparities in angiography rates between different parts of the province. The chief medical officer himself acknowledged that patients with the most vociferous doctors sometimes received their bypass earlier than might have otherwise been the case. We consider it likely therefore that who a patient's doctor is contributes significantly to chances of referral to hospital and ultimately to the timeliness of revascularisation. Thirdly, the scenarios which were drawn from the GPs appraisal were obviously artificial and required consideration of only the particular characteristic in question. Reality is far more complex. Nevertheless, "paper evaluation" has been shown to distinguish substantial variations in clinical practice in the management of patients with chest pain ${ }^{29}$ and may circumvent other biases."

Therefore we hope that this work can form the basis of further inquiry into how doctors weight various sociodemographic patient characteristics in reaching decisions about the need for angiography and revascularisation assessment. The results of this study are being used to inform the discussions of the regional Clinical Resource Efficiency Support Team $(\mathrm{CREST})^{31}$ which will advise on the development of local referral criteria. Though they have their detractors, ${ }^{32}$ consensus methods for developing practice guidelines have attracted a large amount of published work. ${ }^{33}$ What has become clear, however, is that while coherently gathered published evidence can inform the production of guidelines ${ }^{35}$ " the utilisation of guidelines may be more contingent on a sense of ownership among the "stake holding" clinicians. ${ }^{37}$ It must be remembered that waiting lists are now the ultimate responsibility of the purchaser and coronary artery bypass procedures are included in the budget of GP fundholders. GPs, particularly those practising in closely knit or rural communities may be particularly susceptible to pressures from their most vociferous patients. They may know many of them socially, and the difficulty of objectively applying practice guidelines should not be underestimated.

Thus, in the light of our results concerning the effects of demographic characteristics on the perceptions of benefit and priority, it may be time to look closely at which types of patients will reap the benefits of expanding the service.

We thank the following ( $\mathrm{PP}$ advisors at each health board for their advice and help: Drs $M$ Brown (Western), S Gille (Southern), C Booth (Eastern), M Eakin (Northern). A complete copy of the questionnaire is available from the authors.

1 Revice of cardiac surgery in Northern Ireland. A report by the Chicf Medical Officer. Belfast: Department of Health an Social Services, 1992

2 Kee F. Referrals for coronary angiography in a high risk population. Quality in Health Care 1993;2:87-90.

3 Kee F, Gaffney B, Currie S, O'Reilly D. Access to coronary catheterisation: fair shares for all? BMF 1993;307: $1305-7$.

4 Elder AT, Shaw TRI), Turnball (.M, Starker IR. Elderl and younger patients selected to undergo coronar and younger patients selected to

5 Kirklin JW, Akins CW Blackstone EH, Booth DC, Califf RM, Cohen LS, $i t$ al. ACC/AHA Task Force report. Guidelines and indications for coronary artery bypass graft surgery. 7. Am Coll Cardiol 1991;17:543-89. 5h Vornauskas E and the European Coronary Surgery Study Group. Twelve rear follow up of survival in the randomised European Coronary Surgery Study. Nio Engl F Med 1988;319:332-7.

6 Patterson DLH, Treasure T. The culprit coronary artery lesion. Lancut 1991;338:1379-80.

Weston CFM, Watura R, Reeves P, Fraser A(i. Do patient with heart disease sanction medical paternalism? Br Hiall 7 1993;69(suppl): Abstract 237.

\& Hope T, Sprigings D), Crisp R. "Not clinically indicated": patients" interests or resource allocation?" B.117 1993 $306: 379-81$.

9 Kilner JF. Age criteria in medicine: are the medical justifications ethical? Arch Intem Med 1989;149:2243-6. 10 Wetk ' 1 . Age as a risk factor for inadequate treatment 7.AMA 1987;258:516.

11 Umachandran V, Ranjadayalan K, Ambepityia (i Marchant B, Kopelman P( $\mathrm{B}$. Aging, autonomic function and the perception of angina. Br Heart f 1991;66:15-8.

12 Petticrew M. Mckee M, Jones J. Coronary artery surgery are women discriminated against? B.117 j(9)3;306 11040.

13 Harris RB, Weissfeld LA. Gender differences in the reliability of reporting of sumptoms of angina pectoris. Clin Epidemiol 1991;44:1071-8.

$1+$ Birdwell BG, Herbers JE, Kroenke K. Evaluating chest pain. The patient's presentation style alters the phrsicians diagnostic approach. Arch Intern Med 1993 $15 \dot{3}: 1991-5$

15 Lerner DJ, Kannel W'B. Patterns of coronary heart diseas morbidity and mortality in the sexes: a 26 year follow-up of the Framingham population. Am Hear of 1986 111:383 90.

16 Feibach NH, Viscoli (.M, Horwitz RI. Differences between women and men in survival after myocardial infarction. Biology or methodology? 7AMA 1990;263:1092 6.

17 Orencia A, Bailey K, Yawn B. Kottke 'T. Feffect of gender on long term outcome of angina pectoris and mocardial infarction/sudden unexpected death. FAMA 1993;269 infarction

18 Bickell NA, Pieper KS, Lee KL, Mark DB, (Glower DD) Pryor DB, ot al. Referral patterns for coronary artery disease treatment: gender bias or good clinicil judgement? Ann Intern .1 led 1992:116:791 7

19 Fitzgibbon GM, Leach AJ, Kafka HP. Atherosclerosis of coronary bypass grafts and smoking. (in Med Asioc $1987: \mathbf{1 3 6}: 457$

20) Nietzel GF, Baboriak JJ, Pintar K, Quershi I Atherosclerosis in aortocoronary bypass grafts. Morphology study and risk factor analysis $6-12$ year after surgery. Arteriosicleresi: 1986;6:594-600

21 Ramanathan KB, Vander Zwaag R, Maddock V, Kroetz $\mathrm{H}$ Sullivan JM, Mirvis DM. Interactive effects of age and other risk factors in long term survival after coronar artery surgery. F Am Coll Ciardiol 1990;15:1493-9.

22 Bhattacharava $S$. Higher complication rates are no confined to smokers. BMI 1993;306:1409

23 Harris J. The zalue of life. London: Routeledge, 1985

24 Williams RB, Barefoot JC, Califf RM, Haney TI, Saunder WWB, Pryor DB, et al. Prognostic importance of social an economic resources among medically treated patients with angiographically documented coronary arter discase. FA.1H 1992;267:520-4.

25 Navlor CD, I crinton C, Baigric RS, Goldman BS. Placin patients in the queue for coronary artery surgery: do age patients in the queue for coronary artery surgery: do age
and work status alter Canadian specialists decisions? and work status alter Canadian

26 Priestly KA, Buller NP. Why so few coronary revascularisation procedures? Br Hicar $f$ 1093;69(suppl) Abstract 238

27 Evans AE, McCrum EE, Patterson C.C. The change of hear bascline clinical surec1. A report to the Health Promotion Agencr. Belfast: Belfast MONICA Project and the Department of Epidemiology and Public Health. Queen's University of Belfast, 1990

28 Faculty of Public Health Medicine and Yorkshire Regional Health Authority. Implementing "Health of the Nation" An cxample: ischacmic heart discase. Yorkshire Regional An crample: lichacmlc

29 Hlatk . MA, I ee K, Botrinick E, Brundage BH. Diagnostic test use in different practice settings: a controlled comparison. Arch Intern Med 1983:143:1880-9

30 Bobbio . M, Detrano R, Shandling A, Ellestad M, Clark J Brezden O, it al. Clinical assessment of the probability of coronary artery discase: judgemental bias from personal knowledge. Med Decis Making 1992;12:197 203

31 McClements P. Clinical Resource Efficiency Support Tean (CREST). Health Trends 1993;25:46.

32 Oliver MF. Consensus or non-consensus conferences on coronary heart disease. Lancet $1985 ; \mathrm{i}: 1087-9$

33 Fink A, Kosecoff J, Chassin M, Brook R. Consensus methods: characteristics and guidelines for use. Am Public Health 1984;74:979-83.

34 Woolf SH. Practice guidelines, a new reality in medicine. II Methods of developing guidelines. Arch Intrm Med 1992;152:946 52 .

35 Lomas J, Anderson (G, Enkin M, Vavda E, Roberts R Mackinnon B. The role of evidence in the consensus process. Results form a Canadian consensus exercise. process. Results form a
$\not A M A 1988 ; 259: 3001-5$.

36 Grimshaw J, Russell I. Achieving health gain through clinical guidelines. I. Developing scientifically valid clinical guidelines. I. Developing scientifical
guidelines. Onality in Health Care 1993;2:2+3 8 .

37 Buchan H. Clinical guidelines: acceptance and promotion. Quality in Hialth Care 1993;2:213 4 . 